\title{
Alteridade, vida pública e educação: discussões a partir de Richard Sennet e Zygmunt Bauman
}

\author{
Otherness, public realm and education: discussions from Richard \\ Sennet and Zygmunt Bauman
}

http://dx.doi.org/10.5007/2178-4582.2017v51n1p144

Giuliana Franco Leal

Universidade Federal do Rio de Janeiro, Rio de Janeiro/RJ, Brasil

\begin{abstract}
Neste artigo, estabelece-se uma relação entre a educação e as dificuldades de construção de formas civis de convivência entre pessoas estranhas umas às outras, no mundo contemporâneo. A pesquisa, teórica, baseia-se em textos de Richard Sennet e Zygmunt Bauman sobre a crise na vida pública. Os objetivos são responder, acrescentando reflexões próprias às suas obras: (a) Como se dá uma crise na vida pública entre os séculos XX e XXI? (b) Quais são suas consequências sociais? (c) Existem alternativas àquela crise, das quais a educação - em especial a educação formal, no ensino básico - possa participar? Como? Um olhar sobre a realidade mostra que a educação tende a se voltar a finalidades privadas, mas a escola pode ser também um dos instrumentos de fortalecimento da vida pública, por caminhos aqui discutidos.
\end{abstract}

Palavras-chave: esfera pública; alteridade; educação.
In this paper, we discuss the rapport between education and the difficulties of construction of civil forms of coexistence between strangers in the contemporary world. The theoretical research is based on texts by Richard Sennett and Zygmunt Bauman about the crisis in public realm. The objectives are to answer the following questions: (a) How is the crisis in public realm on twentieth and twenty-first centuries? (b) What are its social consequences? (c) Are there alternatives to that crisis, in which education - especially formal elementary education - can participate? How can we do it? A look at reality shows that education tends to have private purposes, but the school can also be a way to overcoming this crisis, as we discuss in this paper.

Keywords: public realm; otherness; education.

\section{Introdução}

As últimas décadas do século $\mathrm{XX}$ e as primeiras do século XXI têm apresentado crises dos laços sociais na vida pública: além das relações de trabalho se flexibilizarem e se fragilizarem em grande escala na década de 1990 (CASTEL, 1995; HIRATA, 2007), assistimos ainda a profundas dificuldades na construção de formas civis de convivência entre pessoas estranhas umas às outras, como pretendemos demonstrar ao longo deste texto. A dificuldade de formação de laços sociais fortes para além da vida privada pode ser expressa pelas ideias de declínio da vida pública (SENNET, 1988) e de desintegração da rede social (BAUMAN, 2001), entre outras formulações. A relação entre esse fenômeno e a educação, contudo, tem sido pouco investigada.

Para discutir como e por que esses laços são ou tornam-se frágeis, várias abordagens poderiam ser resgatadas, mas este artigo concentra-se sobre 
aquela que se refere à debilidade da sociabilidade pública, associando-a aos problemas da convivência entre estranhos que compartilham espaços comuns. Esta é uma abordagem pouco explorada nos estudos sobre educação, embora tenha alto potencial reflexivo. Serão privilegiadas as obra de dois autores que colaboram para essa perspectiva - Richard Sennet e Zygmunt Bauman levando em conta as suas contribuições e os seus limites.

A partir de uma análise imanente de suas contribuições, pensaremos na relação da educação com os problemas que envolvem a crise da vida pública. Os objetivos deste artigo são responder, acrescentando reflexões próprias às obras de Sennet e Bauman: (a) Como se dá uma crise na vida pública entre os séculos XX e XXI? (b) Quais são suas consequências sociais? (c) Existem alternativas àquela crise, das quais a educação - em especial a educação formal, no ensino básico - possa participar? De que maneiras?

Faremos inicialmente algumas definições conceituais necessárias à discussão. Em seguida, revisaremos algumas ideias desenvolvidas por outros pesquisadores acerca da relação entre esfera pública e educação. Passaremos então a um exame mais detalhado da crise da vida pública, a partir dos autores escolhidos para abordar o tema (Sennet e Bauman). Com esse embasamento teórico, voltaremos à questão sobre como a educação está relacionada àquela crise na atualidade, discutindo alternativas à mesma, das quais a educação pode participar.

\section{Vida pública e estranhos: definições e abordagens}

Várias definições de vida pública ou esfera pública são possíveis. A partir de levantamento da literatura sobre o tema, Weintraub (1997) percebe que a noção de público define-se em oposição à noção de privado. Segundo o autor, existem duas distinções fundamentais e recorrentes, que podem se combinar de várias maneiras. Em uma delas, está em questão a visibilidade: o público é pensado como aquilo que é aberto, revelado ou acessível - em oposição ao privado, equivalente ao secreto. $\mathrm{Na}$ outra concepção, está em questão a coletividade: público é o que pertence ao domínio coletivo ou afeta a coletividade - em oposição ao privado, referente ao individual ou pertencente ao domínio particular. Ambos os aspectos - visibilidade e coletividade podem se misturar de várias maneiras e até se confundir.

Weintraub (1997) identifica quatro maneiras principais de uso e compressão de público/privado: (a) O modelo da economia liberal pensa a distinção público/ privado em termos da clivagem entre administração do estado e economia de mercado. (b) A perspectiva clássica da virtude republicana vê o espaço público em termos de comunidade política e cidadania. (c) A terceira perspectiva vê 
espaço público como "uma esfera de sociabilidade fluida e polimorfa" (1997, p. 7), analisando as condições culturais que a tornam possível. (d) Entre os estudos feministas, há uma tendência importante de conceber a diferença entre público e privado em termos da distinção entre a família e a ordem econômica e política mais ampla.

Neste artigo, usamos a perspectiva de esfera pública ou vida pública (tratadas como sinônimos) principalmente na terceira acepção mencionada, ou seja, para nos referimos à sociabilidade estabelecida nos espaços de encontro entre estranhos. Em alguns momentos, iremos nos referir à esfera pública como espaço de produção de decisões coletivas, mas neste caso alertaremos para a mudança.

Laços sociais são entendidos como os vínculos que ligam os indivíduos entre si e com o conjunto da sociedade, no sentido apontado por Durkheim (1984). Eles são o cimento que permite a integração de uma sociedade, uma relativa coesão de seu conjunto - que não significa, necessariamente, a inexistência de qualquer conflito.

Por fim, denominaremos estranhos, tal como sintetizado por Ribeiro (2014, p. 24) a partir de um balanço da teoria social contemporânea, "aqueles indivíduos ou grupo de indivíduos que carregam consigo um estigma social, o de não ser conhecido, de não ser familiar, de ser diferente a ponto de evidenciar uma clara distinção entre 'eles' e "nós'". Existem diferentes maneiras pelas quais os indivíduos podem ser considerados estranhos: por serem migrantes, por adotarem comportamentos dissonantes da maioria, por estarem fora dos padrões de determinado grupo; o estranho pode até mesmo ser simplesmente um desconhecido com o qual se depara na rua. A característica comum à categoria "estranho" é causar perturbação, ainda que não intencionalmente, por colocar em questão as regras de agir e os padrões de comportamento que oferecem segurança (RIBEIRO, 2014).

\section{Esfera pública e educação}

Carvalho (2008) constata a pouca importância dada à esfera pública no mundo contemporâneo ocidental, no qual se valorizam prioritariamente as habilidades e realizações individuais. Ele oferece uma reflexão sobre a relação entre esse fenômeno e a educação, a partir dos livros $A$ condição humana e Entre o passado e o futuro, de Hanna Arendt. De acordo com Carvalho (2006, p. 413), a educação escolar é orientada prioritariamente para a formação de competências e habilidades para o mercado, relegando ao segundo plano o "cultivo de princípios éticos ligados às virtudes públicas", tais como a tolerância, a igualdade e a solidariedade. 
A explicação desse fenômeno está fora do âmbito educacional: está na "crescente e contínua diluição das esferas pública e privada na vida contemporânea" (CARVALHO, 2008, p. 413). Esfera pública á aqui compreendida, tal como em Arendt (1999), como uma ordem além da esfera privada e diferente desta. A esfera privada é voltada para a garantia das necessidades de sobrevivência individual, familiar e da espécie, pelo labor. Diferentemente, a esfera pública é orientada para um universo simbólico e material formado pelo artifício humano, permanente e compartilhado entre os seres humanos. No mundo moderno, prioriza-se a esfera privada, colocandose a esfera pública a serviço daquela, na medida em que o que mais importa é o consumo: a consequência para a educação é que ela passa a ser concebida como investimento privado, sem significação pública e política. Isso explica que as habilidades e competências para o mercado sejam mais valorizadas do que a formação dos sujeitos para a vida política, e que o currículo escolar seja tecnicista (CARVALHO, 2008). Assim, Carvalho mostra as consequências para a educação da prioridade da esfera privada sobre a pública, mas não se propõe a discutir se e como a educação poderia participar da reversão da fragilidade da esfera pública.

Streck (2006), pelo contrário, ocupa-se em pensar como a educação pode contribuir para a (re)construção do público. Para o autor, a educação também tem contribuído para a fraqueza da esfera pública, embora não seja a única nem a maior responsável. Por outro lado, a educação é um dos instrumentos possíveis, se aliado a outros, para traçar o caminho contrário.

A educação de que Streck (2006, p. 274) fala é a educação popular, desde a década de 1980 não mais restrita a sindicatos, grupos dentro de igrejas e outros grupos e entidades populares, mas incorporada "ao fluxo da política e da pedagogia". O autor considera que um dos grandes temas geradores da educação popular é justamente "a construção pública do bem comum", visto que "a educação popular procurou ser uma prática político-pedagógica de formação do público a partir de um lugar que se identificava com quem estava de fora ou por baixo da escala social, dependendo das teorias explicativas do popular" (p. 276).

Em busca de condições hoje existentes para gerar "um ethos que propicie condições efetivas de participação", Streck (2006, p. 277) resgata de Bonamusa ${ }^{1}$ o esboço de tendências pelas quais a educação popular pode contribuir para a formação e o fortalecimento de "uma cultura do público": em especial, o fortalecimento dos movimentos sociais e organizações populares e a geração de capacidade de interlocução qualificada com o governo, fortalecendo a sociedade civil.

1 BONAMUSA, M. Que es la sociedade civil? Uma mirada a Colombia. In: Londoño, L. F. et.al. Sociedad civil, control social y democracia participativa. Bogotá: Tecer mundo Editores, 1997, p. 1965-1968. 
Sua abordagem não visa especificamente a educação formal, isto é, a escola. Este é o tema do qual pretendemos nos ocupar, a partir da perspectiva de dois autores que discutem amplamente a fragilidade da vida pública, mas que têm sido pouco apreciados sob esses aspectos no campo da educação Richard Sennet e Zygmunt Bauman.

\section{Esfera pública e alteridade em Richard Sennet}

A obra de Richard Sennett tem como questão recorrente a crise da vida pública. Embora haja algumas mudanças em algumas de suas visões no decorrer de sua produção, não nos deteremos sobre elas, e sim sobre aspectos convergentes de sua obra.

A decadência da vida pública é associada à ascensão da incivilidade especialmente no livro $O$ declínio do homem público. Sennet (1988) entende que a civilidade corresponde a uma forma de relacionamento impessoal que estimula a troca de ideias sem intimidade. Consiste, assim, em condição essencial para a convivência e o estabelecimento de diálogo entre estranhos. Em outras palavras, civilidade tem o significado de

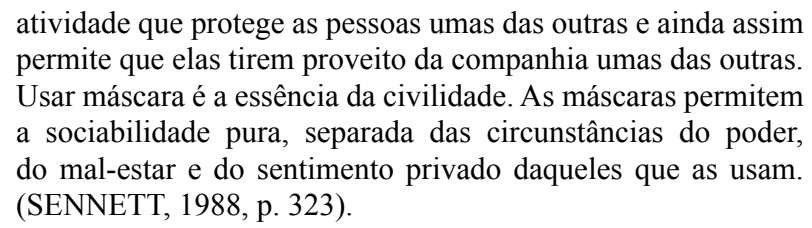

Em termos inversos, incivilidade consiste em "sobrecarregar os outros com o eu de alguém" (SENNET, 1998, p. 324). A incivilidade está presente, por exemplo, em tornar mais importantes as características pessoais das lideranças políticas carismáticas do que os seus atos concretos na vida política, bem como na fraternidade baseada na identidade e empatia entre um grupo de pessoas (por bairro, por região, por etnicidade, etc) que exclui outros.

A incapacidade de estabelecer relação civil é construída, segundo Sennet, a partir da "formação de uma nova cultura urbana, secular e capitalista" (1988, p. 30), ligada às condições materiais que se constroem entre os séculos XVIII e XX. A vida citadina moderna é marcada pelo aumento da população urbana e, portanto, do contato entre estranhos. Nessas condições, todos se deparam constantemente não só com a desigualdade, mas também com a diversidade.

Uma reação do homem citadino moderno - especialmente o burguês frente à sensação de estranhamento e de caos que o crescimento e diversidade 
dessa população urbana, é a retração em público, resguardando a intimidade dos olhares alheios, e a retração para a esfera privada e comunitária. Assim, estão dadas as condições para a passividade pública: evitam-se manifestações em público e diálogos com estranhos. Gera-se, assim, uma crise das formas de expressão impessoal. A maioria das pessoas torna-se espectadora da vida pública, enquanto os papéis públicos ficam reservados a poucos - artistas e políticos profissionais (SENNET, 1988).

Segundo Sennet, a contrapartida necessária dessa passividade pública é a pessoalidade exacerbada, ou seja, a expansão da personalidade a todos os domínios da vida humana. No bojo dessa visão, está o entendimento de que a personalidade é imanente às aparências, que fornecem pistas para o sentimento privado. Mais ênfase passa a ser dada à aparência como expressão da personalidade do que aos discursos e ações na vida pública.

Ao fim do período analisado, temos o triunfo da personalidade individual sobre a coletividade. As principais consequências apontadas por Sennett (1988) são as dificuldades de convivência entre estranhos e de lidar com interesses de forma efetiva por meio dos procedimentos políticos. Buscase a intimidade, exponencialmente valorizada, fugindo-se de tudo o que representa a impessoalidade da vida pública. A busca de comunidades onde se pratique a intimidade torna-se uma oposição à convivência intensa numa sociedade mais ampla.

Enfim, a tese de Sennet (1988) é de que, por meio de um longo processo histórico de erosão do equilíbrio entre vida pública (o terreno do impessoal) e vida privada (o terreno do pessoal), a tirania da intimidade - pensada como supervalorização da aproximação entre pessoas e da personalidade, em função do mito de que os males da modernidade provém da impessoalidade resulta em frustração da sociabilidade, em diminuição do terreno público da significação impessoal e da ação impessoal.

Com isso, no âmbito do poder institucional, se dá mais atenção à personalidade dos políticos do que aos verdadeiros interesses envolvidos e aos jogos desses interesses. No âmbito das aglomerações em que vivemos, a comunidade torna-se uma defesa contra sociedade, implicando em retraimento político em relação a ela. Essas duas maneiras de pensar e agir fazem com que as forças de dominação e a iniquidade não sejam atacadas. Além disso, as pessoas não se sentem à vontade diante da diversidade de experiências que formam uma cidade - o que constitui a marca de uma sociedade incivilizada.

Em suma, fazendo a relação entre as formas como se manifesta a sociabilidade pública e a esfera política de tomadas de decisões, Sennett mostra que o enfraquecimento do saber e da prática de como se relacionar 
publicamente com outros leva a dois tipos de dificuldades: na convivência entre estranhos e na participação consciente no jogo político, em todas as esferas que envolvem tomadas de decisões em um sistema institucional democrático.

O primeiro grupo de dificuldades, da convivência entre estranhos, fazia muito sentido no momento em que o livro foi publicado pela primeira vez (1974), com o grave quadro de desigualdade social em nível mundial e a sombra do pós-guerras. Hoje o problema permanece atual, seja pelas desigualdades sociais que levam à espiral de apartação e violência social, seja pelos conflitos étnicos que se mantém ao redor do planeta ou pelas discriminações a minorias.

Todavia, existe uma novidade quanto aos encontros entre estanhos: eles ganham possibilidade de se tornarem mais frequentes e desterritorializados na medida em que avança a popularização da Internet. Marques (2006) lembra que a Internet favorece a troca de experiências e conteúdos, propiciando a cidadãos distantes encontros virtuais que podem levar a discussões de questões de interesse público. Porém, diferentes posições se apresentam quanto à Internet como esfera pública, entre seus estudiosos. Em um polo, estão autores para quem os espaços discursivos digitais compõem a esfera pública, podendo estimular novas modalidades de formação cívica e de ação política. Em outro polo, estão autores que consideram que as discussões na internet são frequentemente carentes de racionalidade e de civilidade, não possibilitando unidade em busca de consenso, como seria essencial à esfera pública. Uma terceira visão mostra a internet como possível esfera pública virtual de debate público para formação de opiniões, ainda que longe de uma esfera pública ideal, por ser permeada por atitudes não democráticas, como exclusões e ofensas.

Enfim, na Internet, a incivilidade no diálogo é recorrente. Há ainda a exposição frequente da intimidade, em oposição à impessoalidade necessária à riqueza da vida pública, tal como concebida por Sennet. Portanto, a Internet apresenta-se mais como espaço potencial do que real de uma vida pública marcada pelo encontro civil entre estranhos.

$\mathrm{O}$ segundo grupo de dificuldades apontadas - relativas à participação consciente no jogo político - também se mantém atual. Mas a evolução do processo de declínio da vida pública e sua relação com a esfera de tomada de decisões coletivas são esclarecidas por Sennett (1988) em apenas alguns aspectos que ele seleciona em seu método, o qual consiste em acompanhar as mudanças na valorização atribuída às vidas pública íntima pelo estudo comparativo das mudanças de papéis nos palcos e nas ruas das cosmópolis. O livro não discute aquela esfera em si, nem essa tarefa é empreendida pelo autor em outra parte de sua obra. Além disso, nesse livro, um elemento muito importante no tema das transformações do capitalismo permanece excluído: 
o trabalho. Este elemento, porém, é central em livros posteriores de Sennet, que focam nas consequências da economia capitalista contemporânea para as vidas humanas.

Tanto no livro A corrosão do caráter (2005) como em A cultura do novo capitalismo (2012), Sennett mostra aspectos de como a economia capitalista contemporânea, gerando incertezas e impedimentos aos planejamentos de longo prazo (na economia e nas vidas pessoais) ameaça as relações e os laços sociais. Sennett (2012) revela mecanismos pelos quais essa mesma lógica da produção e dos intercâmbios econômicos conduz à passividade face à vida política.

A economia capitalista das últimas quatro a cinco décadas tem como um de seus pilares a flexibilidade em três sentidos: (a) reinvenção descontínua de instituições: mudança das relações de trabalho de forma a romper com o padrão fordista anterior; (b) especialização flexível, focando em produtos variáveis e ilhas de produção especializadas, nas quais as tarefas se modificam com rapidez; (c) concentração de poder sem centralização, nas estruturas econômicas. Associada à flexibilidade, está a aceitação da fragmentação (SENNETT, 2005).

Face à incerteza, ficam ameaçados ou impossibilitados os planejamentos de longo prazo nas vidas profissionais e pessoais. Como manter então princípios que demandam tempo para serem construídos, tal como compromisso e confiança? Como manter relações sociais duráveis? pergunta Sennett (2005).

O panorama que Sennett (2012) traça é de uma cultura baseada nas expectativas de curto prazo, como ideal cultural. Os resultados de curto prazo começam como meta do capitalismo da transição do século XX para o XXI, impõem-se aos trabalhadores e se alastra para a política, acompanhada por indivíduos que se tornam espectadores e cidadãos passivos. Plataformas políticas são produzidas à semelhança das demais mercadorias, orientadas para a produção rápida de resultados.

Além disso, cidades são projetadas para isolar as diferenças, evitando contatos, conflitos e confrontos - entre bairros comerciais e de habitação, entre pobres e ricos, diferenças étnicas etc. Por meio dessa forma de isolamento segregador, bem como do isolamento pelo retraimento em público,

é possível reduzir-se a complexidade da experiência urbana. Afastando-se dos outros, e mediante um conjunto de clichês, o cidadão sente-se mais à vontade; ele pressente a realidade e desloca o que lhe parece confuso ou ambíguo. (SENNETT, 2014, p. 368). 
Dessa forma, Sennett revela mecanismos pelos quais estranhos são tratados com distância devido ao medo e este faz com que a distância se perpetue. Isso impede que as pessoas pensem em interesses comuns ou convergentes, negociem interesses divergentes e, enfim, possam conduzir verdadeiramente juntas, em processo de negociação, as decisões da vida coletiva.

\section{Esfera pública e alteridade em Zygmunt Bauman}

Também Bauman $(2001 ; 2003)$ tematiza, a partir da dissecação da cultura contemporânea, a dificuldade de estabelecerem-se laços sociais fortes. Essa dificuldade se expressa dentro da noção de "modernidade líquida", caracterizada por mudanças constantes na organização coletiva e nas vidas individuais. Fluidez e liquidez são metáforas para o presente estágio da modernidade. O "derretimento dos sólidos" é característica permanente da modernidade e foi se intensificando.

Bauman (2001) corrobora o argumento de Sennett de que a fluidez das relações, associada à mentalidade de curto prazo, corrói as bases possíveis do estabelecimento de compromissos. Daí a desintegração das redes sociais, levando à ascensão de um modo de individualismo incompatível com a busca de soluções coletivas para problemas criados coletivamente, mas vivenciados individualmente.

Poucos são os espaços em que pode-se praticar a civilidade. Esta tem como principal característica a capacidade de interagir com estranhos sem utilizar essa estranheza contra eles nem pressioná-los a deixar de lado traços que os fazem estranhos. Inversamente, multiplicam-se os espaços públicos não-civis e os não-lugares (BAUMAN, 2001).

Bauman (2001) toma o conceito de não lugar de Augé, como "um espaço que não pode se definir nem como identitário, nem como relacional, nem como histórico" (AUGÉ, 2012, p. 73). Construídos em função de certos fins (transporte, trânsito, comércio, lazer), os não-lugares são impessoais a ponto de não deixarem espaço para qualquer diálogo não utilitário.

Há outros espaços públicos não-civis que Bauman (2011) distingue, onde estranhos se encontram sem ter de praticar a civilidade. São assim espaços de passagem como certas praças, projetada de modo a que ninguém se detenha ali e espaços de compras/consumo, onde as pessoas praticam atos individuais.

Bauman resgata de Lévi-Strauss (1981) duas estratégias humanas para lidar com a alteridade: antropoêmica e antropofágica. A primeira consiste em 
expulsar para longe o que é diferente. Suas formas recorrentes consistem em separação de espaços físicos. Por sua vez, a estratégia antropofágica visa a aniquilação da alteridade, como fazem os centros de consumo (BAUMAN, 2001). Ambas as estratégias negam a convivência profunda com a diferença. Conforme se intensifica o impulso para a uniformidade, o medo dos estranhos aumenta.

\begin{abstract}
A capacidade de conviver com a diferença, sem falar na capacidade de gostar dessa vida e beneficiar-se dela, não é fácil de adquirir e não se faz sozinha. Essa capacidade é uma arte que, como toda arte, requer estudo e exercício. A incapacidade de enfrentar a pluralidade dos seres humanos e a ambivalência de todas as decisões classificatórias, ao contrário, se autoperpetua e reforçam: quanto mais eficazes a tendência à homogeneidade e o esforço para evitar a diferença, tanto mais difícil sentir-se à vontade em presença de estranhos, tanto mais ameaçadora a diferença e tanto mais intensa a ansiedade que ela gera (BAUMAN, 2001, p. 123).
\end{abstract}

\title{
Educação, estranhos e vida pública
}

Bauman (2009) discute o papel a ser assumido pela educação na "modernidade líquida". Em discursos hegemônicos, como o da Comissão Europeia para a Educação e Cultura, pressupõe-se que o conhecimento é importante em função da competitividade das empresas. Por outro lado, a mesma comissão declara - e Bauman concorda - que o objetivo principal da educação é capacitar cidadãos a "fazer escolhas e atuar efetivamente sobre as escolhas feitas" (BAUMAN, 2009, p. 161), influenciando o ambiente ao redor. Isso envolve a "reconstrução do espaço público, (...) onde homens e mulheres possam se engajar numa tradução contínua dos interesses individuais e comuns, privados e comunais, direitos e deveres" (p. 162).

Assim, a educação deve ser uma preparação para uma vida política ativa, ou seja, para a cidadania, para que a figura cidadão deixe de ser tão abafada pelo papel do consumidor. Para isso, é necessário conhecer e compreender a realidade, em termos das causas sociais de problemas hoje vivenciados.

Essa formulação sobre uma cidadania ativa que torne o mundo melhor para os homens e mulheres é interessante, mas um tanto vaga. As questões que Bauman coloca sobre estranhos e vida pública trazem mais problemas para o campo da educação, que merecem ser pensados com mais cuidado - ainda que ele não se proponha a isso. $\mathrm{O}$ mesmo ocorre com as questões levantadas por Sennet sobre aquele tema. 
Questão central apontada por ambos os autores é a pouca prática da civilidade no mundo moderno. Uma vez que estão raros, nas sociedades ocidentais contemporâneas, os espaços de convivência civil entre estranhos (BAUMAN, 2001; SENNET, 1988), a escola pode ser um espaço privilegiado para o aprendizado da convivência entre diferentes e para a prática do diálogo pautado no respeito à diferença - ou seja, para a construção de um modelo de civilidade. Para atingir esse objetivo, algumas vias podem ser interessantes.

A primeira começa pela oportunidade, dada pela escola, da convivência com a diferença e a promoção do respeito à diversidade. Com a divisão brasileira entre escolas privadas, frequentadas pelos filhos da maior parte das famílias que podem pagar por elas, e escolas públicas, frequentadas por quem tem menos poder aquisitivo, já existe uma clivagem de desigualdade no ensino básico, com uma separação entre as classes médias e baixas, sendo os pobres, os estranhos, por excelência para as classes média e alta durante toda a modernidade.

A superação dessa segregação exige mudanças estruturais que tornem as escolas públicas reconhecidas por sua qualidade e/ou as instituições de ensino privadas acessíveis a todos, por exemplo, pela erradicação da pobreza. Enquanto isso não ocorre, alternativas para a não transformação das escolas em parte dos guetos que separam as classes sociais seria a criação de oportunidades de encontros sistemáticos, com objetivos educacionais, entre estudantes de diferentes escolas, bem como a abertura das escolas para atividades culturais que envolvessem outros setores da sociedade além de seus próprios estudantes, de modo integrado.

Mas além da classe, há outros marcadores sociais de diferença que podem existir dentro da escola, tais como raça, gênero, orientação sexual (SOUZA, 2006), além de religião e outras diferenças culturais. Para uma sociedade que lide com seus estranhos sem que seja de forma antropoêmica ou antropofágica (no sentido conferido por Lévi-Strauss), o respeito à diversidade deve ser um tema interdisciplinar de estudo, e sua aceitação, uma meta.

Além disso, dada a falta da prática do diálogo nas sociedades contemporâneas, pode ser a escola uma espaço por excelência de aprendizado e exercício do diálogo. Se existem dificuldades de raciocínio em torno de interesses impessoais e de expressão impessoal, como indica Sennet (1988), é necessário que sejam aprendidos, por meio do exercício: a identificação dos interesses e princípios imbricados nos diferentes projetos e propostas políticos; o reconhecimento, por cada um, dos próprios valores e interesses; sua transformação em projetos; o confronto impessoal de ideias; a busca de 
pontos comuns entre posições diferentes; a identificação de divergências; a negociação entre propostas e projetos distintos.

Por fim, a educação formal básica pode contribuir para a superação da crise da vida pública por mais duas vias: pela incorporação do conhecimento das formas de participação em esferas públicas de formação e tomada de decisões hoje existentes (desde conselhos até as esferas deliberativas dos poderes constituídos) ao currículo escolar e pela construção do conhecimento e da habilidade criativa e crítica necessária para pensar outras vias possíveis de participação pública a serem construídas. Para isso, não basta pensar no conteúdo do currículo escolar e deixar de lado a maneira como ele se constrói. Se a forma como se organiza a vida pública moderna estimula a passividade (SENNETT, 1988), é necessário que a escola realize um movimento contrário: que os estudantes não sejam receptores passivos de um conteúdo, mas que atuem ativamente no processo de ensino-aprendizagem, questionando, pesquisando, construindo respostas e soluções.

\section{Considerações finais}

Vimos que a escola, como parte da sociedade, é perpassada pelas suas tendências dominantes, entre as quais destacamos a orientação para a formação voltada ao mercado (BAUMAN, 2009; CARVALHO, 2008), condizente com a prioridade, dada no mundo contemporâneo, à esfera privada em detrimento da vida pública (CARVALHO, 2008; SENNET,1988).

A escola não é, porém, elemento passivo nos jogos de força em curso. Os agentes que a compõem são sujeitos que podem usar a educação para promover transformações. Nesse sentido, ainda que a escola frequentemente seja reprodutora de normas sociais, é cada vez mais necessário pensá-la sob a ótica das suas potencialidades transformadoras, inclusive como um dos possíveis focos de resistência a visões de mundo dominantes. É nesse sentido que pensamos e propomos a escola como espaço de aprendizado ao respeito à diversidade e de construção do diálogo entre diferentes.

\section{Referências}

ARENDT, Hanna. Entre o passado e o futuro. São Paulo: Perspectiva, 1978.

A condição humana. Rio de Janeiro: Forense Universitária, 1999.

AUGÉ, Marc. Não-lugares: Introdução a uma antropologia da sobremodernidade. Lisboa: Bertrand, 2012. 
LEAL, Giuliana Franco. Alteridade, vida pública e educação: discussões a partir de Richard Sennet e...

CARVALHO, I. C. de Moura. As transformações da esfera pública e a ação ecológica: educação e política em tempos de crise da modernidade. Revista Brasileira de Educação, Brasilia, DF, v. 11, n. 32, p. 308-315, maio/ago. 2006.

CARVALHO, J. S. F. O declínio do sentido público da educação. Revista Brasileira de Estudos Pedagógicos, Brasilia, DF, v. 89, n. 223, p. 411-424, set./dez. 2008.

CASTEL, Robert. Les metamorphoses de la question sociale: une chronique du salariat. Paris: Fayard, 1995.

DURKHEIM, É. A divisão do trabalho social. Lisboa: Editorial Presença, 1984.

BAUMAN, Z. O mal estar na pós-modernidade. Rio de Janeiro: Zahar, 1998.

. Modernidade líquida. Rio de Janeiro: Zahar, 2001.

Comunidade: a busca por segurança no mundo atual. Rio de Janeiro: Zahar, 2003.

. Vida líquida. Rio de Janeiro: Zahar, 2009.

HIRATA, H. Flexibilidade, trabalho e gênero. In: HIRATA, H.; SEGNINI, L. (Orgs.). Organização, trabalho e gênero. São Paulo: Editora Senac. 2007, p. 89-107.

LÉVI-STRAUSS, C. Tristes trópicos, Lisboa/São Paulo: Ed. 70/Martins Fontes, 1981.

MARQUES, F. P. J. A. Debates políticos na Internet. Opinião Pública, Campinas, v. 12, n. 1, abr./mai. 2006.

RIBEIRO, L. Estranhos no mundo contemporâneo: exclusão social, preconceito e intolerância. Curitiba: Appris, 2014.

SENNETT, R. O declínio do homem público: as tiranias da intimidade. São Paulo: Companhia das Letras, 1988.

. A corrosão do caráter: consequências pessoais do trabalho no novo capitalismo. Rio de Janeiro, São Paulo: Record, 2005.

. A cultura do novo capitalismo. Rio de Janeiro: Record, 2012.

Carne e pedra: o corpo e a cidade na civilização ocidental. Rio de Janeiro: BestBolso, 2014.

SOUZA, E. R. Marcadores sociais da diferença e infância: relações de poder no contexto escolar. Cadernos Pagu, n. 26, p. 169-199, jan./jun. 2006.

STRECK, D. A educação popular e a (re)construção do público. Há fogo sobre as brasas? Revista Brasileira de Educação, v. 11, n. 32, p. 272-284, maio/ago. 2006.

WEINTRAUB, J. The theory and politics of the public/privated distinction. In: WEINTRAUB, J.; KUMAR, K. (Eds.). Public and private in thought and practice: perspectives on a grand dichotom. Chicago: The University of Chicago Press, 1997. p. 01-42. 
Submissão em: 28/09/2015

Aceite em: 05/09/2016

Giuliana Franco Leal é professora da Universidade Federal do Rio de Janeiro. Mestre e doutora em Sociologia pela mesma universidade.

Fez estágio pós-doutoral em Ciências Sociais na Educação, na Unicamp (2011) Endereço: Universidade Federal do Rio de Janeiro, Campus de Macaé. Av. Aluizio da Silva Gomes, 50. Granja dos Cavaleiros. CEP 27930-560. Macaé/RJ, Brasil. E-mail: giulianafrancoleal@yahoo.com.br 